\title{
A fotografia não foi inventada, e sim descoberta
}

\author{
Juliana Winkel \\ Jornalista, especialista em Gestão da Comunicação pela ECA-USP. Mestranda em Ciências da \\ Comunicação pela ECA-USP e editora executiva da revista Comunicação Ẽ Educação. \\ E-mail: juli.santos@usp.br \\ Izabel Leão \\ Jornalista atuando como repórter do Jornal da USP. Mestre em Ciências da Comunicação pela \\ Escola de Comunicações e Artes da USP. Pesquisadora do Núcleo de Comunicação e Educação \\ da ECA-USP. \\ E-mail: izabelwiz@gmail.com
}

Resumo: O fotógrafo, professor e pesquisador Boris Kossoy fala sobre sua carreira como acadêmico e profissional da fotografia. Comenta, ainda, seu trabalho como pesquisador da obra do desenhista francês Hercule Florence, discutindo as vantagens em atuar simultaneamente na pesquisa e junto ao mercado, bem como dos desafios e diferenças de visão de ambos os campos.

Palavras-chave: Fotografia, desenho, história, Hercule Florence.
Abstract: Photographer, professor and researcher Boris Kossoy speaks about his career as an academic and professional photographer. He also comments on his research on the work of French designer Hercule Florence, discussing the advantages of operating simultaneously in research and in the market, as well as the challenges and different angles of both fields.

Keywords: Photography, design, history, Hercule Florence.

Como fotógrafo profissional, Boris Kossoy tem uma trajetória de destaque. À frente de seu próprio estúdio fotográfico, "AMPLIART", prestava, nos anos de 1960, serviços para veículos de comunicação como Rede Record, Rádio Jovem Pan e Jornal da Tarde. Primeiro brasileiro a participar da ASMP (American Society of Magazine Photographers), teve várias de suas fotografias incorporadas a acervos como os do Museum of Modern Art e o Metropolitan Museum of Art, em Nova Iorque. É autor de inúmeras obras de referência centradas na investigação histórica e teórica da imagem, como Fotografia e história ${ }^{1}$, Realidades e ficções na trama fotográfica ${ }^{2} e$ Os tempos da fotografia ${ }^{3}, e$, com a obra Hercule Florence: a descoberta isolada da fotografia no Brasil ${ }^{4}$, alcançou reconhecimento internacional por incluir o país no cenário dos precursores da fotografia.

Com a pesquisa sobre Florence, que viveu na Vila São Carlos - atual cidade de Campinas - entre 1829 e 1879, Kossoy comprova que o desenhista francês, radicado e isolado no Brasil, teve papel importante na descoberta do processo fotográfico, derrubando

1. KOSSOY, Boris. Fotografia e história. São Paulo: Ateliê Editorial, 2001.

2. Id. Realidades e ficções na trama fotografica. São Paulo: Ateliê Editorial, 2002.

3. Id. Os tempos da fotografia. $O$ efêmero $e$ o perpétuo. São Paulo: Ateliê Editorial, 2007.

4. Id. Hercule Florence: a descoberta isolada da fotografia no Brasil. São Paulo: Edusp, 2006. 
comunicação \& educação • Ano XVII • número 2 • jul/dez 2012

o paradigma de que o francês Louis Jacques Mandé Daguerre seria o único no mundo a desenvolver este processo. "A fotografia não foi inventada, e sim descoberta", afirma Kossoy, que, em virtude da pesquisa, foi condecorado com a distinção Chevalier de l'Ordre des Arts et de Lettres pelo Ministério da Cultura da França.

Neste depoimento, além de tratar desse tema, ele discorre sobre a importância da fotografia e sobre nosso condicionamento contemporâneo em relação à palaura escrita, ainda que tenhamos a imagem multissecular com todos os seus códigos específicos, como meio de informação, circulação e emoção.

\section{O OLHAR COMO REGISTRO}

Meu interesse em relação à imagem veio primeiro através das histórias em quadrinhos - e logo se expandiu para o desenho, o cinema e a fotografia, convivendo juntos. Creio que é impossível, mesmo, pensar nesse tipo de imagem sem remontar à literatura, que também foi uma de minhas primeiras fontes de inspiração. Na verdade, me interessava tudo que fosse relacionado à ficção, desembocando no realismo mágico, fantástico, que pouco se explorou no Brasil. Na minha cabeça, desde garoto, a fotografia e o cinema andavam de mãos dadas. Eu desenhava bem, creio que sempre fui bastante inventivo, e isso veio a se expressar nas fotos também. Conforme fui amadurecendo, a junção dessas ideias despertou meu interesse pela arquitetura. No período JK vivia fascinado, assim como outros jovens da minha geração, pela proeza de Brasília, pelo surgimento de uma cidade ultramoderna no meio do nada. Em 1961 prestei vestibular e entrei na Faculdade de Arquitetura do Mackenzie, uma instituição que era parte da minha vida desde os tempos do ginásio e do científico, como se falava na época. A opção pela arquitetura foi importante para a minha formação, porque aprofundou em mim algo que eu já tinha latente - a imaginação espacial, sentir o espaço, pensar o passado, mas não de forma abstrata, e sim dentro de lugares, de edificações.

A partir daí, as coisas foram acontecendo concomitantemente. O interesse pela pesquisa científica, por exemplo, veio da curiosidade em saber mais sobre esse nosso universo - onde começa, onde acaba, qual sua idade, quantas galáxias tem. Ficava empolgado desde menino, quando ouvia falar que existem tantos astros no universo quantos grãos de areia em todas as praias do mundo... ou então sobre a existência de vida em outros planetas. Esses mistérios todos constituíram um casamento de ideias e reflexões que me levaram ao caminho da pesquisa. O método científico, baseado sempre na busca de conhecimentos, observação, experimentação e dedução, foi impulsionado com o Iluminismo na França, em uma época em que a religião tinha sido deixada de lado e se buscavam formas de controle e domínio sobre a natureza segundo preceitos científicos.

No século XIX, o pensamento foi muito influenciado com o Positivismo de Comte, valorizando tudo que pudesse ser quantificado, comprovado materialmente - o que beneficiou, obviamente, as ciências biológicas e exatas. 
Em relação às ciências humanas, porém, engessava toda a possibilidade de reflexão e interpretação. A história válida, portanto, seria aquela narrada segundo uma sucessão de documentos submetidos a uma rigorosa crítica de fontes, na busca do dado exato, da prova perfeita.

Mais tarde, isso nos iria levar a algumas linhas perigosas de pensamento e ação - desembocando no darwinismo social, no racismo e, já no século XX, no fascismo e nas teses nazistas que pregavam a superioridade do ariano puro e a inferioridade de negros, judeus e ciganos no século XX.

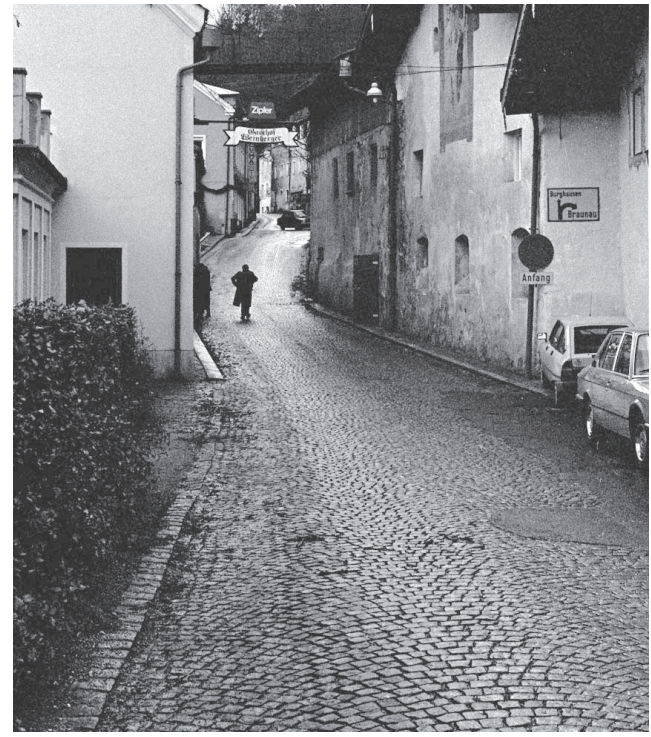

(Leverkusen-Alemanha) - Boris Kossoy, 1983

Todas essas pseudociências,

e ciências de fato, me interessavam enquanto pesquisador. No livro $O$ olhar europeu ${ }^{5}$, por exemplo, que escrevi a quatro mãos com a historiadora Maria Luiza Tucci Carneiro, fomos buscar na produção da imagem, e naquilo que ela reflete, os códigos discriminatórios e racistas. Esses aspectos, em geral, passam despercebidos porque as pessoas consideram a imagem como ilustração e não como documento expressivo da história, como portador de informações decisivas - que, na maioria das vezes, não são tomadas como pistas ou, muito menos, decifradas.

O documento e a ficção, dessa forma, aparecem no meu trabalho sempre ora um, ora outro -, e eu os considero processos que se retroalimentam, porque temos a ficção acontecendo em nossas vidas todos os dias, basta ler os jornais. Uma das funções da imagem, em tempos remotos, era o embelezamento, a ilustração, o adorno sobre um determinado fato de forma ficcional, fantasiosa. Aí reside, inclusive, um equívoco conceitual profundo: perdeu-se um tempo imenso atribuindo-se à imagem, unicamente, a função ilustrativa, "artística", e com isso ela foi remetida ao anexo, ao apêndice dos livros e da história.

Em Fotografia e história ${ }^{6}$, eu chamava a atenção sobre isso. Tenho certeza, porém, de que hoje se começa a pensar diferente. Não se pode tentar, por exemplo, analisar o progresso na cidade de São Paulo sem observar as mudanças sociais ou arquitetônicas. É preciso ver as fotos de Militão Augusto de Azevedo, feitas no século XIX, e compará-las com as de Guilherme Gaensly, já no século XX, para entender as transformações na sociedade e a presença da mão de obra do imigrante estrangeiro trabalhando na arquitetura, na expansão da cidade, no alargamento das vias públicas e demais melhoramentos urbanos. Não se pode precisar essas mudanças apenas com a descrição verbal, porque

5. CARNEIRO, Maria Luiza Tucci; KOSSOY, Boris. O olhar europeu: o negro na iconografia brasileira do século XIX. São Paulo: Edusp, 2002.

6. KOSSOY, Boris. Fotografia e história. São Paulo: Ática, 1988 (edições revistas e ampliadas da obra foram publicadas pela Ateliê Editorial em 2001, 2003 e 2009). 
comunicação \& educação • Ano XVII • número 2 • jul/dez 2012

7. Foram eles o I Encontro - Pensamento e reflexão na fotografia, realizado no Museu da Imagem e do Som (MIS), sob a organização de Geórgia Quintas e Alexandre Belém realização do Estúdio Madalena, sob a direção de latã Canabrava; e, na USP, ○ I Seminário interno do NEIIM (Núcleo de Estudos Interdisciplinares de Imagem e Memória) órgão vinculado ao LEER/ $\mathrm{FFLCH}$, que conta com apoio do PPGCOM-ECA. a compreensão vai só até onde a imaginação alcança. Porém, no momento em que se vê a evolução realmente ocorrendo, através das imagens fotográficas, é que se percebe o sentido da história. Essas imagens trouxeram à compreensão fatores econômicos, sociais e culturais que, até então, eram pura abstração. Hoje, a importância da imagem é algo que se leva em conta - fazendo parte, inclusive, da própria exigência dos alunos para a compreensão da história.

Também no campo científico, percebemos que a fotografia está presente de forma diferente do que acontecia no passado. Hoje existe a preocupação em se discutir a imagem para além de seu sentido de expressão artística. Se antigamente se falava, no máximo, na história da fotografia, hoje se discute tudo em relação às imagens, justamente pela avalanche visual de que vimos sendo objeto nas últimas duas décadas, particularmente após o advento da internet. $\mathrm{O}$ ensino de fotografia tem progredido como decorrência desse interesse. A maioria das escolas ou cursos superiores de fotografia, por exemplo, surgiu nos últimos dez anos. Penso que toda essa movimentação acerca do porquê da imagem, e de como ela pode ser, ao mesmo tempo, tão abrangente e específica, acontece pelo fato de sermos transportados para o interior de fenômenos de macro e microdimensões, nos fazendo descobrir novos universos. Por aí podemos perceber e sentir os caminhos pelos quais a fotografia tem enveredado como forma de ficção e meio de expressão artística, documental e científica.

O Brasil também tem acompanhado essa corrente. Exposições de fotografia brasileira têm sido solicitadas no exterior, enquanto eventos bastante recentes e densos acerca da reflexão sobre o papel da fotografia nas mais diferentes áreas têm ocorrido com mais constância que em anos passados, tanto na academia como fora de seus muros. Esses fatos comprovam o maior interesse que parece se abrir à fotografia.

Só no mês de maio de 2011, poderíamos citar dois exemplos desse momento especial que tiveram lugar em São Paulo ${ }^{7}$. Porém, tenho a impressão de que ainda falta um maior aprofundamento do tema, por meio de publicações e estudos sobre a imagem. Essa área carece de maior atenção e também de se perceber que, assim como ocorre com o conhecimento escrito, existem diferentes métodos e abordagens para se compreender e estudar a realidade. Muitas vezes se considera, inocente ou ingenuamente, que uma foto é "certa" e outra não. Porém, isso não se aplica à imagem, pois não estamos tratando de ciências exatas, e sim de ciências humanas e de arte - e, portanto, de abordagens que têm, como um de seus elementos constituintes básicos, a subjetividade. Temos tratado dessas questões há vários anos através de livros, cursos e debates na universidade, como também nos encontros regionais e anuais em diversas partes do país, promovidos pela Rede de Produtores Culturais da Fotografia no Brasil. O que sinto ainda, no entanto, é uma percepção desencontrada. As pessoas querem fazer cursos porque acham que vão "melhorar". De fato, independentemente de quem estiver ministrando os cursos, as pessoas vão adquirir mais conhecimentos, mas isso não é suficiente. Até mesmo o contato verbal e comunicativo em sala de aula dependerá, sempre, da motivação do aluno em se aprofundar no aspecto que está sendo estudado. 


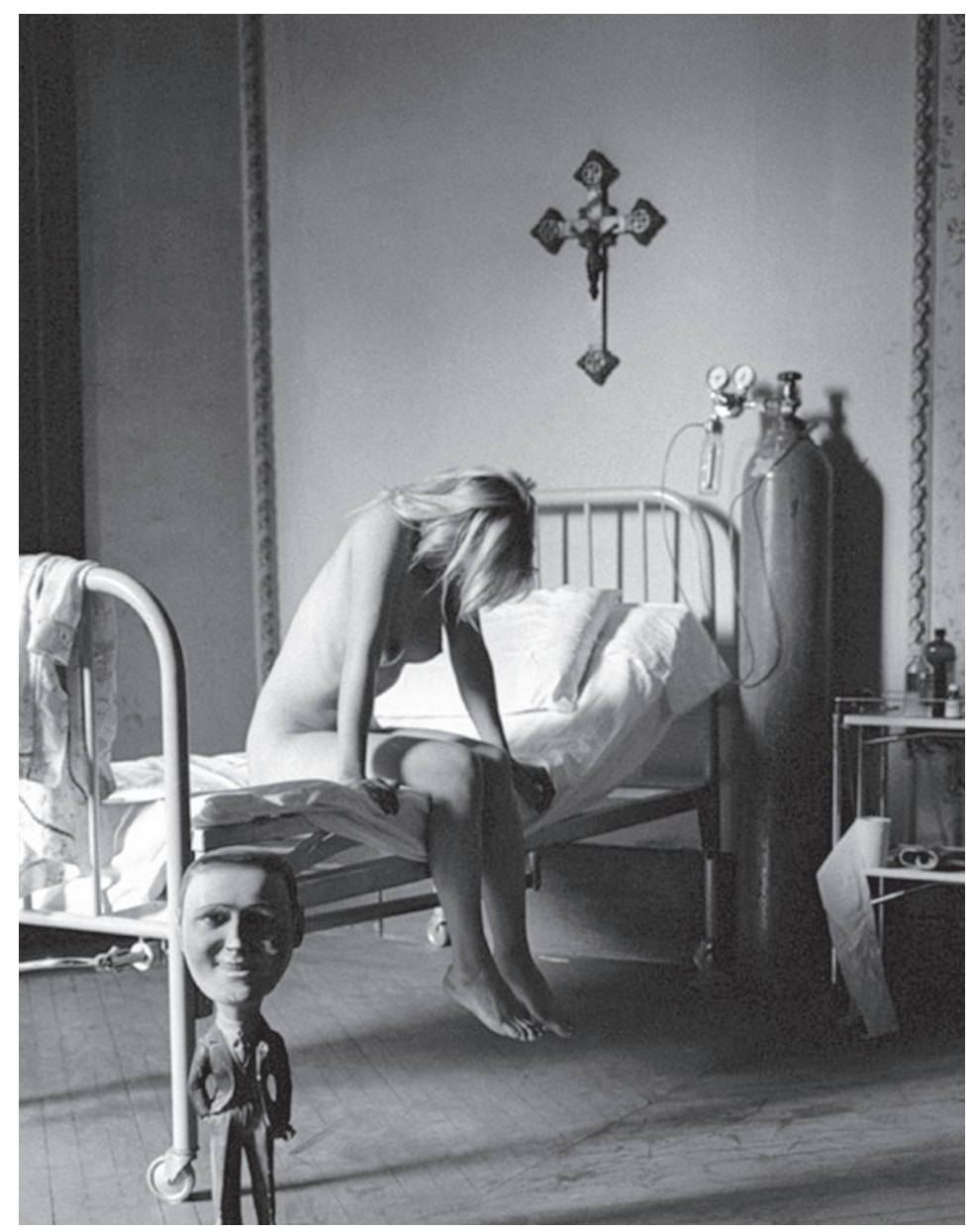

A clínica (da série Viagem pelo Fantástico) - São Paulo, 1970

\section{FLORENCE E UMA ANALOGIA HISTÓRICA}

Toda grande descoberta ou pesquisa transformadora acaba mexendo com o animus, com os modos de pensar, com ideias já cristalizadas. Entre os próprios pesquisadores brasileiros, seja por desconhecimento ou alguma outra razão que não vale a pena investigar, por vezes não se menciona que, entre os descobridores da fotografia, existe um que desenvolveu um processo fotográfico no Brasil, chamado Hercule Florence. Enquanto isso, numa faculdade em Nova York, no Instituto de Tecnologia de Rochester ou em alguma escola europeia, Florence é dado como um dos inventores da fotografia. Isso é, ao mesmo tempo, instrutivo e trágico.

Alunos e pesquisadores muitas vezes se perguntam por que Florence não fazia fotografias da natureza. Isso ocorre porque, devido às condições do meio, ele se preocupou mais em usar o processo para copiar desenhos ou 
comunicação \& educação • Ano XVII • número 2 • jul/dez 2012

textos. Florence ficou fascinado com a ideia de poder imprimir pela ação da luz - imprimir literalmente falando, porque estamos tratando de uma pequena vila chamada São Carlos, dentro de uma província cuja capital também não passava de uma vila: São Paulo, muito antes de seu desenvolvimento econômico em função do café. A vila de São Carlos (depois Campinas) ainda estava muito afastada de um tempo em que iria dispor de escolas superiores. Em São Paulo, existia somente a academia de Direito. Dessa forma, o conhecimento físico, matemático, químico, de engenharia, arquitetura e as ciências de forma geral eram absorvidos através de livros que vinham da Europa.

Todo artista ou inventor é fruto do meio, independentemente daquilo que traz de criativo ou de conhecimento em si mesmo. Florence buscava, em um ambiente inculto e que não dispunha de meios de impressão, uma forma barata de imprimir, factível e possível de ser realizada em qualquer lugar. $\mathrm{E}$ tinha conhecimento dos princípios da câmera obscura, como todo artista dos séculos XVIII e XIX. Dessa forma, fez experiências nesse sentido - mas, devido à própria imperfeição de sua câmera obscura, muito rudimentar, percebeu que os raios de luz passavam por vários pontos mal vedados em suas paredes e se projetavam no papel sensibilizado colocado em seu interior. Então concluiu: se o sol imprime em substâncias fotossensíveis, ele poderia também ser um agente para imprimir desenhos, textos ou escritos de uma forma geral.

Quando viu que seu método funcionava e que havia descoberto um processo fotográfico de reprodução de imagens e desenhos, descreveu isso em seus manuscritos. De qualquer forma, desenvolver esse processo não era sua prioridade inicial. Aí reside nossa questão: é muito possível que, vivendo na França, Florence jamais tivesse tido essa preocupação. Talvez ele tivesse desenvolvido o desenho de forma natural, assim como o interesse por outras áreas do conhecimento. Talvez tivesse se tornado professor de uma universidade francesa, ou um exímio pintor - mas a história não admite o "SE": foi assim porque foi assim. No meio em que viveu, ele encontrou a motivação para seguir adiante nas experiências com a "impressão" pela luz solar. O resultado é que, na década de 1830, Florence imprimia diplomas maçônicos, etiquetas para farmácia e materiais para outras atividades comerciais "em série", por contato de uma matriz de vidro em papel fotossensível, sob a ação da luz solar. Analisando esse fenômeno sob uma perspectiva social, a obtenção de exemplares impressos por seu sistema, naquele preciso momento, era mais útil e importante que o uso da câmera obscura para registrar imagens da natureza.

Do ponto de vista histórico e artístico, temos um tema rico na obra de Florence. Porém, pensando na história sob uma postura positivista, podemos concluir que o que sobreviveu e se consagrou é o que, de fato, importa, enquanto o restante não interessa - o que não deixa de ser uma cruel e oportunista interpretação de fatos históricos não consagrados pela ideologia dominante. A história tem essa face escura e enganosa em relação a tudo que não sobreviveu, que não foi institucionalizado. As informações que não se incluem na versão oficial, dessa forma, são consideradas notas de rodapé. 
Conheci essas questões de perto, também, no âmbito dessa própria pesquisa, por volta dos anos 1970. Hoje compreendo melhor, em função desse modo de pensar, o stress e a polêmica que ela causou. Até hoje a participação de Hercule Florence encontra resistência em algumas correntes de pesquisa, pois é muito mais cômodo se apoiar nas histórias oficiais. É uma maneira, também, de se constatar as mentes colonizadas. A tarefa do historiador é a de pesquisar sempre por documentos ainda não conhecidos, de forma a trazer à luz fatos que permaneceram soterrados, no obscurantismo. Aceitar ou não aceitar novos fatos, novas descobertas, tomá-las ou não como referências já não cabe mais ao historiador. A obra caminha por si, tem sua própria autonomia. Hoje há um interesse muito grande por parte dos estudiosos da imagem, tanto no Brasil como em outras latitudes, pelas realizações de Florence e pelo inusitado que elas representam no contexto da história cultural.

\section{RECONSTRUINDO A HISTÓRIA}

Minhas pesquisas andaram por diferentes caminhos como o do Proin, projeto desenvolvido pelo Arquivo Público do Estado de São Paulo e pela Universidade de São Paulo, sobre documentos dos arquivos do Departamento Estadual de Ordem Política e Social (DEOPS) - órgão instituído durante a ditadura militar para controlar os movimentos políticos e sociais contrários ao regime. A mentora do trabalho de pesquisa do Proin, vale lembrar, foi a

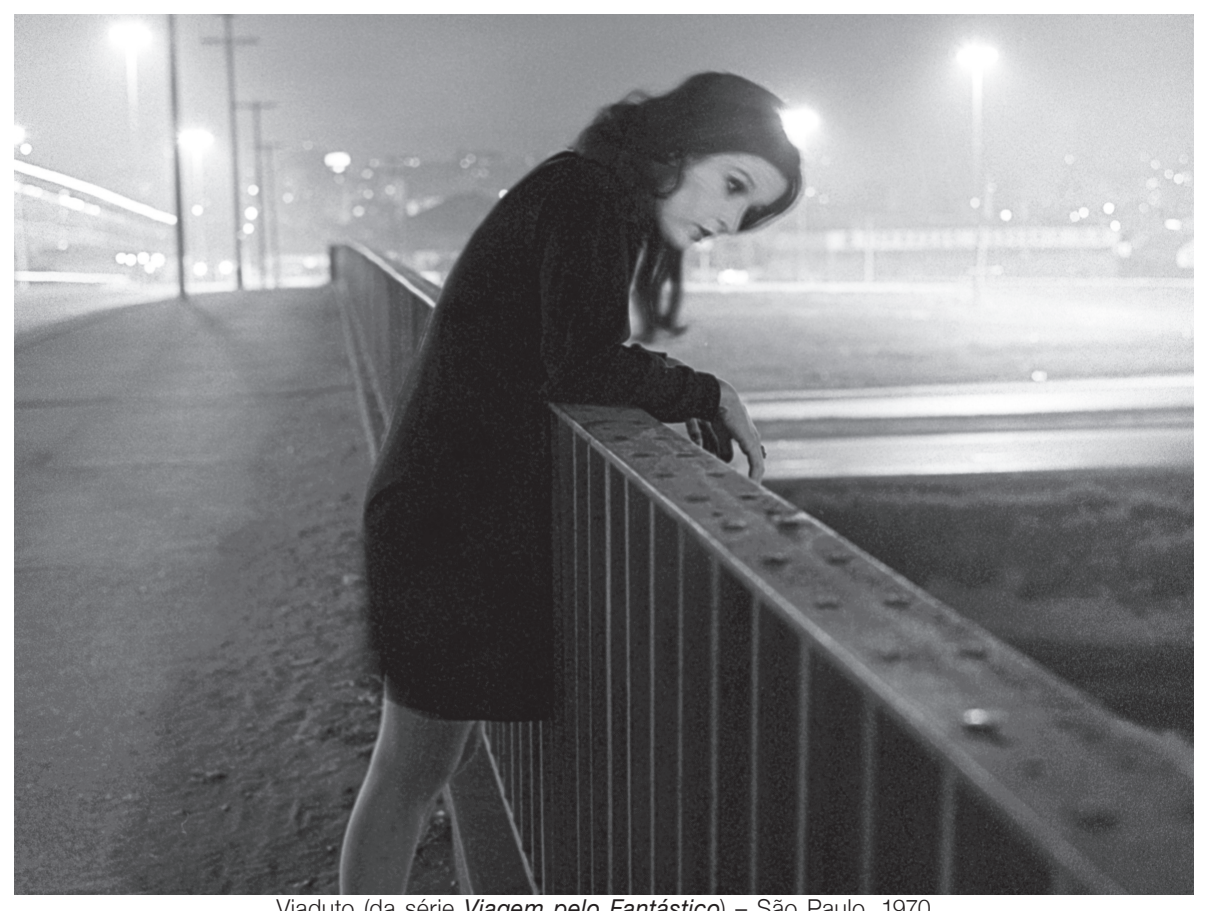

Viaduto (da série Viagem pelo Fantástico) - São Paulo, 1970 
comunicação \& educação • Ano XVII • número 2 • jul/dez 2012

professora Maria Luiza Tucci Carneiro, do Departamento de História da USP. Coube a mim a análise iconográfica dos documentos considerados "subversivos" ou "suspeitos", reunidos nos prontuários da polícia política - e que incluíam desde cartões-postais até retratos de família. Foi um trabalho muito prazeroso, que considero vencedor. Na época do Proin, foram publicados mais de 30 livros trazendo uma nova visão histórico-política do Brasil, através da análise dos documentos pesquisados, abrangendo desde a Era Vargas até o regime militar no Brasil - já que o DEOPS atuou de 1920 até 1980. Ou seja, cerca de 60 anos de repressão, controle e todo o tipo de ações autoritárias.

O trabalho no Proin, acredito, contribuiu também para afirmar a importância da fotografia no acervo documental - principalmente por alertar os historiadores para o estudo a partir da documentação dos prontuários que, em si, mostravam o que era considerado subversivo para a polícia. Com isso, percebemos que quem primeiro entendeu a melhor forma de usar a fotografia como acervo documental foram os governos, a imprensa, a polícia e a igreja. A ciência, por exemplo, desde o século XIX buscava uma forma de mostrar a superioridade dos brancos e a inferioridade das demais raças. Já a religião, de forma geral, se apoiou nas imagens como meio de adoração e devoção. Em tempos imemoriais, os homens expressavam desejos e necessidades como o bisão desenhado nas paredes das cavernas. E hoje, percebe-se seu valor também como forma de informação e de crescimento científico.

Após 12 anos de estudos, a pesquisa realizada pelo Proin continua atualmente de forma diferente, porém com objetivos semelhantes, por meio do LEER (Laboratório de Estudos sobre Etnicidade, Racismo e Discriminação), também coordenado pela professora Tucci Carneiro e vinculado ao departamento de História da FFLCH. Ligados ao LEER, estamos desenvolvendo uma extensa pesquisa sobre iconografia e memória, que deu origem ao NEIIM (Núcleo de Estudos Interdisciplinares de Imagem e Memória), do qual sou coordenador. Foi inaugurado em novembro de 2011 e conta com 27 pesquisadores de diferentes partes do Brasil, sendo 90\% mestrandos e doutorandos das áreas de antropologia, comunicação, jornalismo, história e ciências sociais. Estamos bastante animados com esse núcleo, que já nasce com um grupo bastante determinado e competente.

\section{EM TUDO, A FOTOGRAFIA}

Posso dizer que todos os trabalhos desenvolvidos ao longo do tempo tiveram, como base, meu trabalho de fotógrafo. Comecei a fotografar aos 14 ou 15 anos de idade e sempre me senti muito satisfeito ao fazê-lo. Muitas vezes me perguntaram como alguém pode fazer ciência e ficção ao mesmo tempo e, nesse caso, até onde vai a seriedade desta ciência ou a graça dessa ficção. Acredito que minha primeira formação em arquitetura contribuiu muito para que eu imaginasse e trabalhasse com os espaços de uma forma, para mim, ainda desconhecida. A fantasia, a ficção, o "algo além" daquilo que é a imagem, do 
registro puro e simples, são coisas que fazem parte do meu trabalho desde o início. O registro, puramente descompromissado, me recuso a fazer. Meu interesse é pensar a imagem, as diferentes formas e séries que podem ser criadas com ela.

Em 2011, recebi uma homenagem pelos 40 anos do meu livro Viagem pelo fantástico $^{8}$ - e os personagens dessa obra continuam povoando minha cabeça. São seres que criei, à época, sob uma influência forte dos quadrinhos. Também o livro Boris Kossoy: fotógrafo ${ }^{9}$, elaborado em decorrência de uma exposição muito especial - que não quero chamar de "retrospectiva" - montada em 2008 na Pinacoteca do Estado, foi um momento importante por reunir diferentes fases do meu trabalho. Acredito ter obtido sucesso com a fotografia, pois desde os 29 anos de idade já havia três obras minhas na coleção permanente do Museu de Arte Moderna de Nova Iorque. Também existem trabalhos meus no Metropolitan Museum of Art e no Smithsonian Museum de Washington.

Sinto-me feliz pela minha obra fotográfica, assim como quando vejo, ou outras pessoas percebem, nas imagens um fio condutor, um modo de ver a vida que vai passando tão rapidamente diante nós. Cada fotografia é mais uma peça no mosaico, no caleidoscópio que guardamos em nossas mentes e corações e que, em determinada situação, faz aflorar também nossos preconceitos ou nossos desejos. As imagens que produzimos são, ao mesmo tempo, veículo de expressão e fruto desse caleidoscópio que guarda, inconscientemente, sensações e emoções das mais diferentes naturezas. Desse modo, o fio condutor do meu trabalho é também a marca do autor. É uma maneira de traduzir minha visão de mundo sobre a arte, a ciência e, principalmente, a vida.

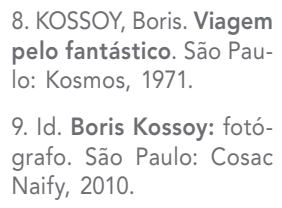




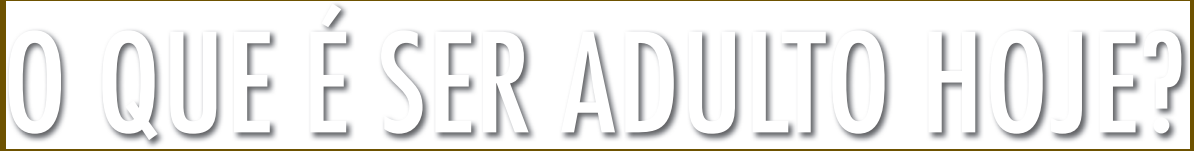

\section{Os aspectos que influenciam a formação do caráter humano}

A obra desenvolvida por Sérsi Bardari apresenta um estudo aprofundado sobre a natureza do público jovem.

0 autor discute os conflitos da juventude, etapa

de transição para uma vida adulta, repleta de responsabilidades, onde o indivíduo se depara com as primeiras cobranças em relação às suas atitudes, começa a abrir mão de algumas regalias, assume mais encargos e começa a depender cada vez mais de si mesmo.

0 livro debate também o papel da produção cultural e da literatura na conquista da maturidade.

Uma leitura fundamental para quem tem o compromisso sociopolítico de formar 0 ser humano, desde a infância e adolescência até a fase adulta.

A ALQUIMIA DO "ADULTESCER" A literatura para juventude como rito de passagem Sérsi Bardari 200 págs. Código: 520977 ISBN: 9788535631142
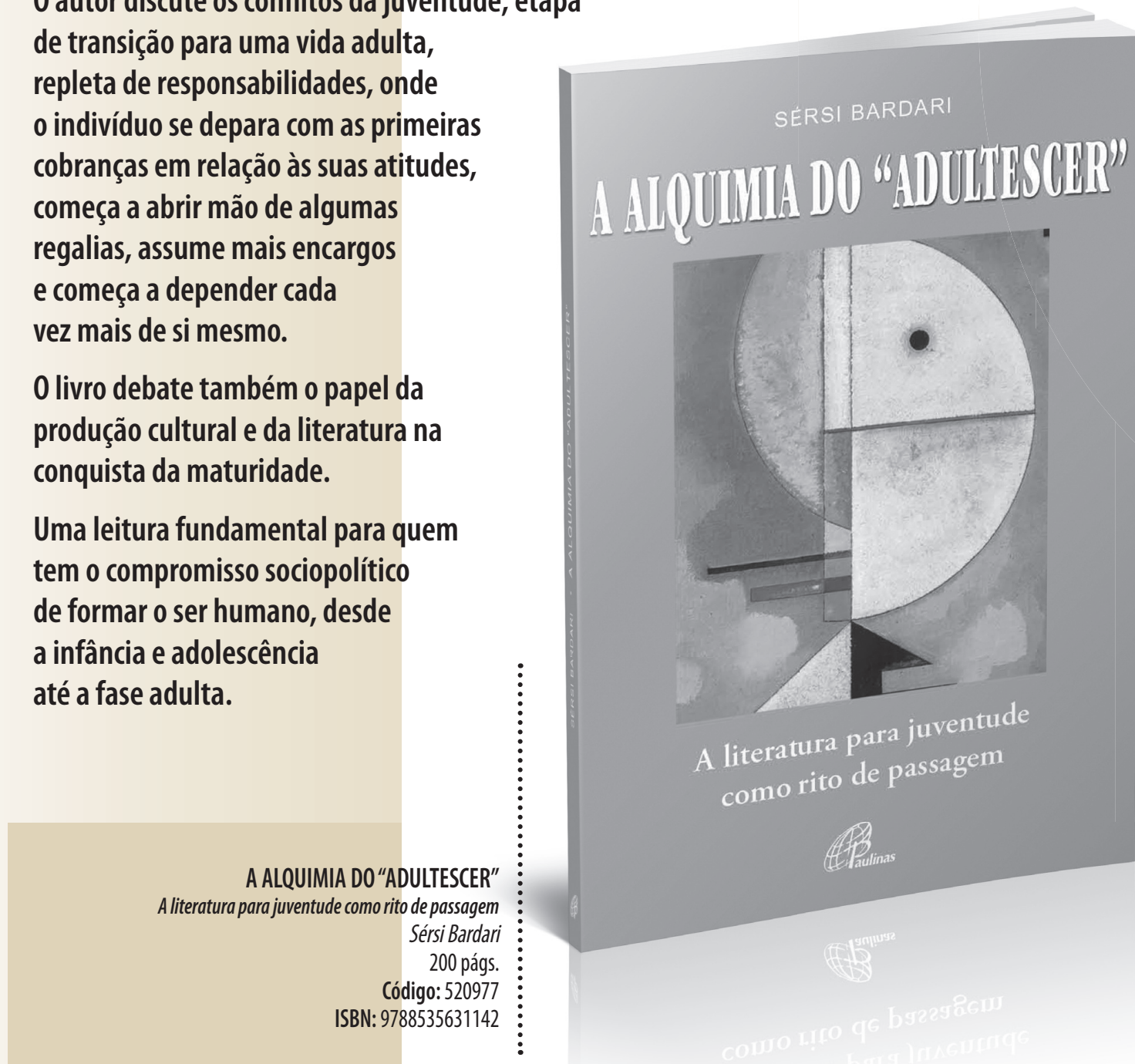